\title{
Deletion of $\beta$-Arrestin2 in Mice Limited Pancreatic $\beta$-Cell Expansion under Metabolic Stress through Activation of the JNK Pathway
}

\author{
Ziwei Lin, ${ }^{1}$ Yu Zhao, ${ }^{1}$ Lige Song, ${ }^{1}$ Kaida Mu, ${ }^{1}$ Mingliang Zhang, ${ }^{1}$ Hongxia Liu, ${ }^{1}$ Xiaowen Li, ${ }^{1}$ Jian Zhao, \\ Chen Wang, ${ }^{1}$ and Weiping Jia ${ }^{1}$ \\ ${ }^{1}$ Shanghai Key Laboratory of Diabetes Mellitus, Shanghai Diabetes Institute, and Department of Endocrinology and Metabolism, \\ Shanghai Jiao Tong University Affiliated Sixth People's Hospital, Shanghai, People's Republic of China; and 'Institute of \\ Biochemistry and Cell Biology, Laboratory of Molecular Cell Biology, Chinese Academy of Sciences, Institutes for Biological Sciences, \\ Shanghai, People's Republic of China
}

\begin{abstract}
$\beta$-Arrestin2 ( $\beta$ arr2) is an adaptor protein that interacts with numerous signaling molecules and regulates insulin sensitivity. We reported previously that $\beta$ arr2 was abundantly expressed in mouse pancreatic $\beta$-cells, and loss of $\beta$ arr2 leads to impairment of acuteand late-phase insulin secretion. In the present study, we examined the dynamic changes of $\beta$-cell mass in $\beta$ arr 2 -deficient ( $\beta$ arr $2^{-/}$) mice in vivo and explored the underlying mechanisms involved. $\beta$ arr $2^{-1}$ mice with exclusively luciferase overexpression in $\beta$-cells were generated and fed a high-fat diet (HFD). $\beta$-Cell mass was determined by in vivo noninvasive bioluminescence imaging from 4 to 20 wks of age. Proliferation was measured by 5-bromo-2-deoxyuridine (BrdU) incorporation and fluorescence-activated cell sorter analysis. Quantitative real-time polymerase chain reaction (qRT-PCR) and immunoblotting were conducted for gene and protein expression. We found that $\beta$-cell mass was reduced dramatically in $\beta a r r 2^{-1}$ mice at $12 \mathrm{wks}$ old compared with that of their respective HFD-fed controls. The percentage of BrdU- and Ki67-positive cells reduced in islets from $\beta$ arr $2^{-/-}$mice. Exposure of $\beta$ arr $2^{-/}$islets to high levels of glucose and free fatty acids (FFAs) exacerbated cell death, which was associated with upregulation of the JNK pathway in these islets. Conversely, overexpression of $\beta$ arr2 amplified $\beta$-cell proliferation with a concomitant increase in cyclinD2 expression and a decrease in p21 expression and protected $\beta$-cells from glucose- and FFA-induced cell death through JNK-activation inhibition. In conclusion, $\beta$ arr2 plays roles in regulation of pancreatic $\beta$-cell mass through the modulation of cell cycle regulatory genes and the inhibition of JNK activation induced by glucolipotoxity, which implicates a role for $\beta$ arr 2 in the development of type 2 diabetes. Online address: http://www.molmed.org
\end{abstract} doi: $10.2119 /$ molmed.2015.00155

\section{INTRODUCTION}

Type 2 diabetes (T2D) is caused by relative insulin deficiency due in part to the reduction of pancreatic $\beta$-cell mass (1-3). The relative $\beta$-cell deficits at the onset of diabetes and impaired glucose tolerance found at autopsy were $64 \%$ and $21 \%$, respectively, indicating that loss of $\beta$-cell mass could exist within the normal glucose tolerance stage (4). However, the initiation of $\beta$-cell loss in humans is difficult to determine, due to the unavailability of current in vivo tracing techniques for $\beta$-cell mass measurement. In addition, the exact mechanisms underlying the loss of $\beta$-cell mass are not fully

$Z L$ and YZ contributed equally to this work.

Address correspondence to Chen Wang, Shanghai Key Laboratory of Diabetes Mellitus, Shanghai Diabetes Institute, and Department of Endocrinology and Metabolism, Shanghai Jiao Tong University Affiliated Sixth People's Hospital, 600 Yishan Road, Shanghai 200233, People's Republic of China. Phone: +86-21-24058657; Fax: 86-21-64368031; E-mail: wangchen@sjtu.edu.cn.

Submitted June 24, 2015; Accepted for publication February 22, 2016; Published Online (www.molmed.org) February 29, 2016.

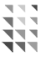
Feinstein Institute
for Medical Research Northwell Health

understood. Identification of key signal molecules involved in regulating $\beta$-cell mass is, thus, essential to reveal potential therapeutic targets in diabetes.

$\beta$-Arrestin2 ( $\beta$ arr2), an adaptor protein ubiquitously expressed in cells, modulates G-protein-coupled receptor desensitization and internalization (5-7). It also functions as a scaffold and mediates the strength and duration of a series of cellular signaling pathways, including modulation of peripheral insulin sensitivity (8-10). We reported previously that $\beta$ arr2 was expressed abundantly in mouse pancreatic $\beta$-cells, and its expression was significantly decreased in obese and diabetic mouse models. Loss of $\beta$ arr2 led to impairment of acute- and late-phase insulin secretion with $\beta$-cell mass tending to decrease in Barr2-null mice (11). 
The roles of $\beta$ arr 2 in the modulation of cell mass have been reported in smooth muscle and hepatic stellate cells $(12,13)$. ßarr2 aggravated atherosclerosis after carotid injury through mechanisms involving smooth muscle cell proliferation (12) and exacerbated hepatic fibrosis induced by porcine serum through its effect on hepatic stellate cell proliferation (13), suggesting a role of $\beta$ arr2 regulation of cell mass expansion under environmental stress. Interestingly, Ravier et al. reported recently that knocking out $\beta$ arr 2 in female mice decreased the $\beta$-cell mass (14). However, how $\beta$-cell mass changes upon $\beta$ arr2 deletion and its mechanism in regulating $\beta$-cell mass still remain largely unknown.

In the current study, using noninvasive bioluminescence imaging (BLI), we traced the dynamics of $\beta$-cell loss in mice with $\beta$ arr2 deletion during the progression of impaired glucose tolerance and explored the underlying mechanisms. As overnutrition is becoming the leading risk factor of T2D, discovering molecules that protect $\beta$-cells against glucolipotoxicity is of great importance to the prevention and treatment of T2D.

\section{MATERIALS AND METHODS}

\section{Animals and Glucose Tolerance Test}

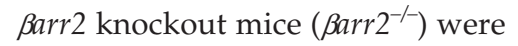
generated and identified as described previously $(15,16)$. Transgenic mice expressing luciferase under the control of the mouse ins2 promoter (MIP-TF) were purchased from The Jackson Laboratory (C57BL/6-Tg[Ins2-luc) EGFP/Tk]300Kauf/J, stock number 012943). MIP-TF- $\beta a r r 2^{-/-}$mice were generated by interbreeding MIP-TF and $\beta a r r 2^{-/-}$mice. Mice were genotyped by polymerase chain reaction (PCR) using primers as described previously $(15,17$; Supplementary Figure S1). Mice were fed either a normal chow diet $(20 \% \mathrm{kcal}$ protein, $10 \% \mathrm{kcal}$ fat and $70 \% \mathrm{kcal}$ carbohydrate; Slaccas Co.) or a high-fat diet (HFD) $(20 \% \mathrm{kcal}$ protein, $45 \% \mathrm{kcal}$ fat and 35\% kcal carbohydrates; Research Diets) from $6 \mathrm{wks}$ of age. They were housed at $23^{\circ} \mathrm{C} \pm 1^{\circ} \mathrm{C}$ under an artificial 12-h light:dark cycle with free access to food and water. All the procedures involving the care and use of animals were in accordance with Shanghai Jiao Tong University Guidelines for the Care and Use of Laboratory Animals (Permit Number SYXK 20110128). The MIP-TF- $\beta a r r 2^{+/+}$and MIP-TF- $\beta a r r 2^{-/-}$ mice were mainly used in the in vivo imaging study; otherwise $\beta a r r 2^{+/+}$and $\beta a r r 2^{-/-}$mice were used. All experiments were performed with male mice, and littermate controls were used throughout this study. Glucose tolerance tests (GTTs) and insulin secretion tests were performed after $12 \mathrm{~h}$ of fasting. Glucose $(1.5 \mathrm{~g} / \mathrm{kg}$ for GTTs and $3.0 \mathrm{~g} / \mathrm{kg}$ for insulin secretion tests) was injected intraperitoneally. Blood samples were taken from the tail vein. Glucose levels were measured using an ACCU-CHEK Performa Glucose Monitor (Roche). Insulin levels were measured using enzyme-linked immunosorbent assay (ELISA) kits (Mercodia).

\section{Islet Isolation, INS-1 (832/13) Cell Culture and Gene Silencing or Overexpression}

Pancreatic islets were isolated from 16-wk-old $\beta a r r 2^{+/+}$and $\beta a r r 2^{-/}$male mice as described previously (18) and cultured in Ham F10 (Gibco, Invitrogen Corp.) supplemented with $6.1 \mathrm{mmol} / \mathrm{L}$ glucose, $0.5 \%$ BSA (charcoal treated) and penicillin-streptomycin. INS-1 (832/13) cells (gift from Yong Liu) were maintained in RPMI 1640 (Gibco) supplemented with $6.1 \mathrm{mmol} / \mathrm{L}$ glucose, 10\% fetal bovine serum (FBS) and $10 \mathrm{mmol} / \mathrm{L}$ HEPES, as described previously (19). Overexpression or knocking down of $\beta$ arr2 in INS-1 (832/13) cells were conducted by infecting the cells with 10 multiplicity of infection adenovirus expressing $\beta$ arr2 (Ad- $\beta$ arr 2 ) or its shRNA (Ad-sh $\beta a r r 2$ ) (gift from Gang Pei; 20). For overexpression of the plasmid expressing c-Jun N-terminal kinase-1 (JNK1) (gift from Yan Lu), INS-1 $(832 / 13)$ cells were transfected with 0.05 or $0.2 \mu \mathrm{g}$ of plasmid expression of JNK1 in $200 \mu \mathrm{L}$ culture medium.

\section{Histology Study and Morphometric Analyses}

Pancreases were removed from 16-wk-old $\beta a r r 2^{+/+}$and $\beta a r r 2^{-/-}$mice, immediately weighed, fixed and embedded. To determine the count and area of islets, 8-10 randomly chosen sections per mouse that were separated by at least $100 \mu \mathrm{m}$ were stained with hematoxylin and eosin (H\&E). The entire pancreatic sections were scanned using a Nikon Eclipse Ni-E Microscope (Nikon), and a tile image of the tissue section was generated using the NIS-Elements AR 4.20 (Nikon). The fractional area of the islet in the pancreas, islet count per unit pancreatic area (islet density) and islet size were manually quantified using Image-Pro Plus 6.0 (Media Cybernetics), as described previously (21). The average of all the sections was taken as a measure for the entire organ. The total islet mass was calculated as pancreatic weight $\times$ mean fractional pancreatic islet area.

For immunofluorescence analysis, pancreatic sections were incubated overnight at $4^{\circ} \mathrm{C}$ with guinea pig anti-insulin antibody (Abcam), followed by staining with secondary goat anti-guinea pig antibody conjugated with Alexa Fluor 488 (Invitrogen). Sections were imaged using a Zeiss AxioImager Standard Microscope (Carl Zeiss).

To analyze cell replication, $\beta a r r 2^{+/+}$ and $\beta a r r 2^{-/}$mice were administered $50 \mathrm{mg} / \mathrm{kg}$ 5-bromo-2-deoxyuridine (BrdU) (Sigma-Aldrich) intraperitoneally, twice daily for $7 \mathrm{~d}$. Immunochemistry of BrdU or Ki67, a cellular marker for proliferation (22), was performed using an anti-BrdU antibody (Boster) and an anti-Ki67 antibody (Abcam) with overnight incubation at $4^{\circ} \mathrm{C}$, followed by incubation with corresponding horseradish peroxide (HRP)-conjugated secondary antibodies. The proliferation rate was represented as the percentage of BrdU- or Ki67-positive nuclei per total islet nuclei.

\section{Cell Viability and Cell Cycle Analysis}

Cell viability was assayed either by Hoechst 33342 (HO; Sigma) and 
propidium iodide (PI; Sigma) staining, as described previously (18), or by flow cytometer analysis. Mice islets from $\beta a r r 2^{+/+}$ and $\beta$ arr $2^{-/-}$mice or $\beta$ arr2-overexpressing INS-1 $(832 / 13)$ cells were exposed to indicated concentrations of glucose or palmitate for 60 or $48 \mathrm{~h}$, respectively. For flow cytometer analysis, the single cell suspension was incubated with Annexin V (Invitrogen) and examined using the Navios flow cytometer (Beckman Coulter).

For the cell cycle analysis, INS-1 (832/13) cells were cultured in $3 \mathrm{mmol} / \mathrm{L}$ glucose without FBS for $6 \mathrm{~h}$ for synchronization and then incubated in $11 \mathrm{mmol} / \mathrm{L}$ glucose with $10 \%$ FBS. After 16 h, cells were harvested for mRNA expression or for cell cycle distribution. The cell cycle phase distribution was determined by the above-mentioned flow cytometer with PI staining.

\section{Microarray Expression Analysis and Quantitative Real-Time PCR}

Gene expression profiles of isolated islets from $\beta a r r 2^{+/+}$and $\beta a r r 2^{-/-}$mice were analyzed with the Affymatrix GeneChip Mouse Genome 4302.0 Array (Affymetrix). Sample preparation and hybridization were done at the Shanghai Biotechnology Corporation (SBC). Microarray data were analyzed using SBC Analysis System (including significant analysis of microarray, fold change, pathway enrichment analyses and hierarchical cluster). Fold changes $\geq 1.4$ and $P$ values $<0.05$ are considered significant difference. Quantitative real-time PCR was performed using the ABI 7500 Fast Real-Time PCR System (Applied Biosystems) as described previously (18). Primers for each target gene are shown in Supplementary Table S1. The relative expression level of each sample was calibrated by the comparative $\mathrm{Ct}$ method, using $\beta$-actin as an endogenous control.

\section{Immunoblotting Analysis}

Protein was extracted from cells with radioimmunoprecipitation assay buffer containing protease inhibitors, separated by sodium dodecyl sulfate-polyacrylamide gel electrophoresis and transferred onto nitrocellulose membranes. The membranes were incubated overnight at $4^{\circ} \mathrm{C}$ with anti-phosphorylated JNK (p-JNK) antibody, anti-total JNK antibody (Cell Signaling Technology), anti-Cyclin D2 antibody (Cell Signaling Technology) and anti-p21 antibody (Millipore), followed by incubation with corresponding HRP-conjugated secondary antibodies. Signals were detected using Fujifilm Luminescent Image Analyzer LAS4000 System (Fujifilm).

\section{BLI}

BLI was performed using a Lumazone Imaging System (Roper Scientific Photometrics) as described previously (23). MIP-TF mice were anesthetized with isoflurane $\left(1.5 \%\right.$ in $\left.98.5 \% \mathrm{O}_{2}\right)$ and injected with $126 \mathrm{mg} / \mathrm{kg}$ of D-luciferin (15 mg/mL in phosphate-buffered saline) intraperitoneally. Then, mice were placed in the supine orientation in a light-tight chamber, and a gray-scale reference image was obtained under low-level illumination. Bioluminescent images were captured 12 min after luciferin injection with an integration time of $3 \mathrm{~min}$. Isometric regions of interest were drawn over the location corresponding to the pancreas for quantification using MAG Biosystems Software 7.6 (MAG Biosystems). Luciferase activity is presented in photon intensity per second. Bioluminescence attenuation was adjusted as described previously by Yong et al. (17).

\section{Statistical Analysis}

Data are expressed as mean \pm standard error of the mean. Statistical analysis was performed with GraphPad Prism 5 for Windows (GraphPad software), and significance was calculated by Student $t$ test or analysis of variance (ANOVA) and followed with Bonferroni correction as appropriate. For all analyses, $P$ values were two-tailed, and $P<0.05$ was considered statistically significant.

All supplementary materials are available online at www.molmed.org.

\section{RESULTS}

\section{Generation and Characterization of MIP-TF- $\beta a r r 2^{-/-}$Mice}

To trace the effect of $\beta$ arr2 on $\beta$-cell mass longitudinally in vivo, MIP-TF- $\beta a r r 2^{-/-}$mice were generated with luciferase expressed exclusively in $\beta$-cells. The MIP-TF overexpression in $\beta$-cells did not affect fasting glucose level and glucose tolerance in the mice (Supplementary Figure S2). However, knocking out $\beta$ arr2 resulted in impaired glucose tolerance (Figures 1A, B) and a defect in glucose-stimulated insulin secretion in these mice under HFD condition (Figure 1C).

\section{Knockout $\beta$ arr2 in Mice Led to Decrease in $\beta$-Cell Expansion under HFD}

To visualize the effect of $\beta$ arr2 on the dynamics of $\beta$-cell mass, MIP-TF$\beta a r r 2^{+/+}$and MIP-TF- $\beta a r r 2^{-/-}$mice fed with either a normal chow diet or a HFD were imaged every $4 \mathrm{wks}$ from 4 to 20 wks of age (Figures 2A, B). In MIP-TF$\beta a r r 2^{+/+}$mice, $\beta$-cell mass represented by bioluminescence intensity increased with the growth of mice fed a chow diet. $\beta$-cell mass reached a plateau at $20 \mathrm{wks}$, 1.9-fold higher than the mass at 4 wks (Figure 2C). This effect was more pronounced when MIP-TF- $\beta$ arr $2^{+/+}$mice were fed a HFD, with a 7.5-fold increase in $\beta$-cell mass at 16 wks (Figure 2D). HFD feeding also induced an increase in $\beta$-cell mass in MIP-TF- $\beta a r r 2^{-/}$mice. However, the increase was much less pronounced, at about half that in MIP-TF- $\beta a r r 2^{+/+}$ mice. The expansion of $\beta$-cell mass in MIP-TF- $\beta a r r 2^{--}$mice ceased at $12 \mathrm{wks}$, which was much earlier than that in their littermate controls (Figure 2D).

To confirm the BLI results above, H\&E staining was performed on pancreatic sections from 16-wk-old $\beta a r r 2^{+/+}$and $\beta a r 2^{-/-}$mice fed both diets (Figure 3A). Compared with their littermate controls, HFD-fed $\beta a r r 2^{-/}$mice also manifested a significant decrease in islet mass, which is associated with decreased islet area and islet density (all $P<0.05)$, but not 

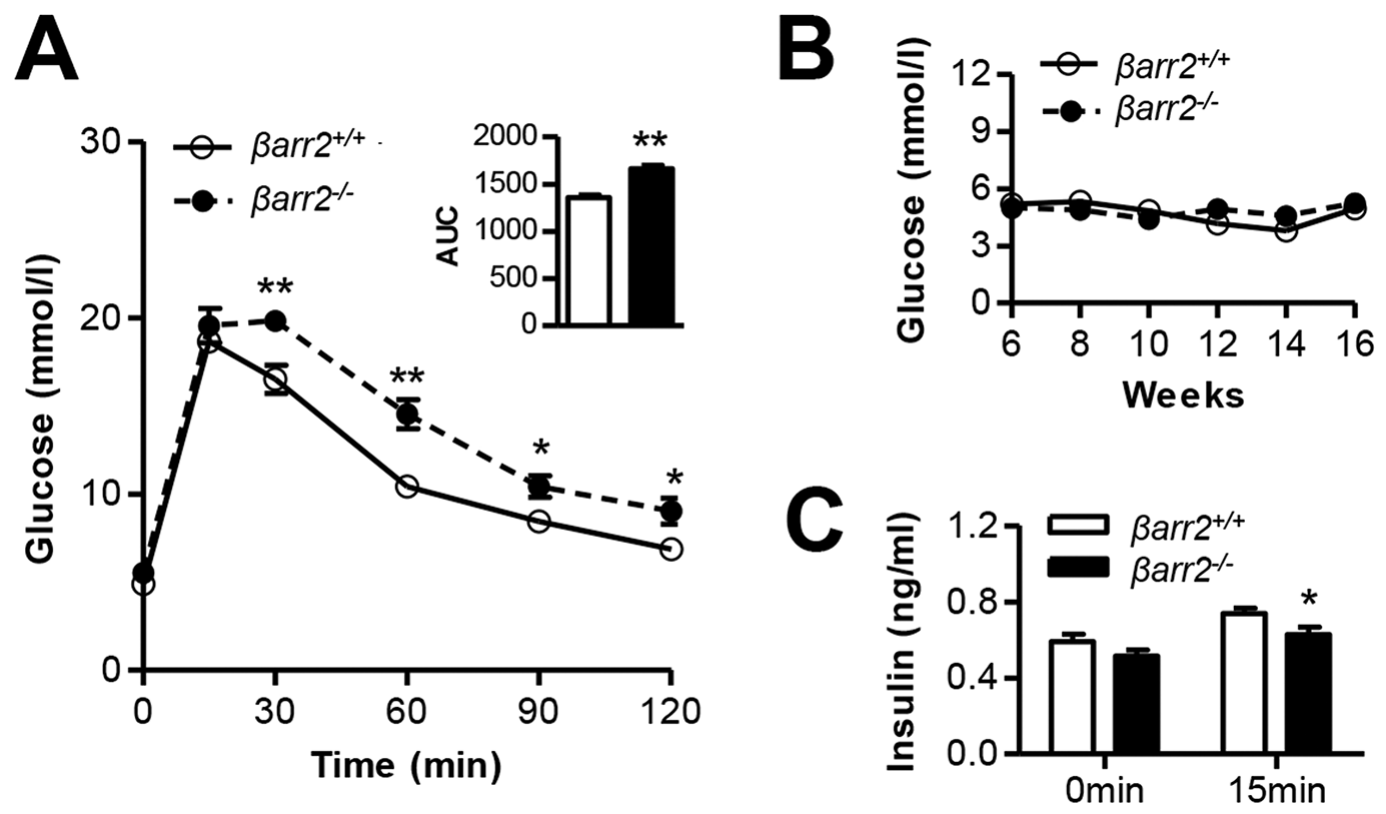

Figure 1. $\beta$ arr2 deficiency results in impaired glucose metabolism and glucose-stimulated insulin secretion in mice under HFD. (A) GT from 16-wk-old HFD-fed MIP-TF- $\beta$ arr2 ${ }^{+/+}$and MIP-TF- $\beta a r r 2^{-1}$ mice $(n=6)$. Insets, area under the curve during GTT. (B) Fasting glucose levels of MIP-

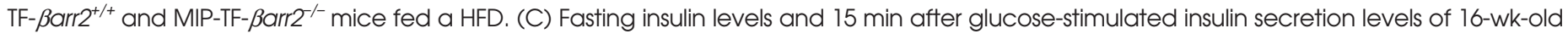
HFD-fed MIP-TF- $\beta a r r 2^{+/+}$and MIP-TF- $\beta a r r 2^{-/-}$mice $(n=8) .{ }^{*} P<0.05,{ }^{* *} P<0.01$, versus MIP-TF- $\beta a r r 2^{+/+}$mice.

with mean islet size (Figures 3B-E).

Further quantification of islet size distribution demonstrated that the number of islets smaller than $0.005 \mathrm{~mm}^{2}$ decreased significantly in HFD-fed $\beta a r r 2^{-/-}$mice (Figure 3F), with only about $65 \%$ remaining. Similar results were obtained by immunostaining pancreatic sections from HFD-fed $\beta a r r 2^{-/}$mice with the anti-insulin antibody; obvious reductions of the insulin-positive areas were observed (Supplementary Figure S3).

\section{Loss of Barr2 Resulted in Decreased Islet Cell Proliferation in Mice}

ßarr2 promotes proliferation in smooth muscle cells and hepatic stellate cells $(12,13)$. Thus, we examined the effect of $\beta$ arr 2 on $\beta$-cell proliferation. As shown in Figure 4A, percentages of both BrdU- and Ki67-positive cells were decreased significantly in islets from $\beta a r r 2^{-/}$mice, exhibiting only $40 \%$ or $53 \%$ of the positive rate of their $\beta a r r 2^{+/+}$ littermates, respectively (both $P<0.05$; Figure 4B). In contrast, overexpression of $\beta$ arr2 in INS-1 (832/13) cells by infecting the cells with Ad- $\beta a r r 2$ significantly increased the relative percentage of cells in the $S$ and $G_{2} / M$ phases of the cell cycle $(23.6 \%$ versus $14.8 \%$ in $3 \mathrm{mmol} / \mathrm{L}$ glucose, and $34.6 \%$ versus $26.5 \%$ in $11 \mathrm{mmol} / \mathrm{L}$ glucose) while decreasing the percentage of cells in $G_{0} / G_{1}$ (Figure $4 C$ ), indicating a role of $\beta$ arr2 in regulation of $\beta$-cell proliferation.

Moreover, in INS-1 (832/13) cells with $\beta$ arr2 overexpression, the mRNA level of cyclin D2 increased by 2.5-fold and the mRNA level of $p 21$ decreased to 0.69 -fold (Figure 4D), both of which encode cell cycle-related proteins that play roles in release of the $G_{1}$ brake on cell cycle progression. Similar trends of changes in protein levels could be observed in the two genes (Figure 4E). No changes could be viewed in the mRNA expression of other $G_{1}$ phase regulators (cyclin D1, Cdk4 and Cdk6), $\mathrm{G}_{1} / \mathrm{S}$ phase regulators (cyclin E1, cyclin E2 and $\mathrm{Cdk2}$ ), $\mathrm{S} / \mathrm{G}_{2}$ phase regulators (cyclin $A 2$ and $C d k 1$ ), and Cdk inhibitors ( $p 18$ and p27) (Figure 4D).

\section{Loss of Barr2 Exacerbated Pancreatic $\beta$-Cell Death Induced by High Levels of Glucose and FFA}

We next examined the effect of $\beta$ arr2 on $\beta$-cell viability in glucolipotoxicity, a condition that occurred during HFD feeding in mice. As expected, exposure of islets or INS-1 $(832 / 13)$ cells to high levels of glucose or palmitate led to cell death compared with that of their respective controls (Figures 5A, B). Deletion of $\beta$ arr2 in islets increased the cell death compared with wild-type islets (Figure 5A), whereas overexpression of $\beta$ arr2 in INS-1 (832/13) cells greatly alleviated the cell death (Figures 5B, C and Supplementary Figure S4). Taken together, our results suggested a role of $\beta$ arr 2 in protection of $\beta$-cells from high glucose- and FFA-induced cell death.

\section{Overexpression of $\beta$ arr2-Protected Cells through Inhibition of JNK Pathway}

To understand the biological processes related to $\beta$-cell survival in $\beta a r r 2^{-/}$mice, 
A

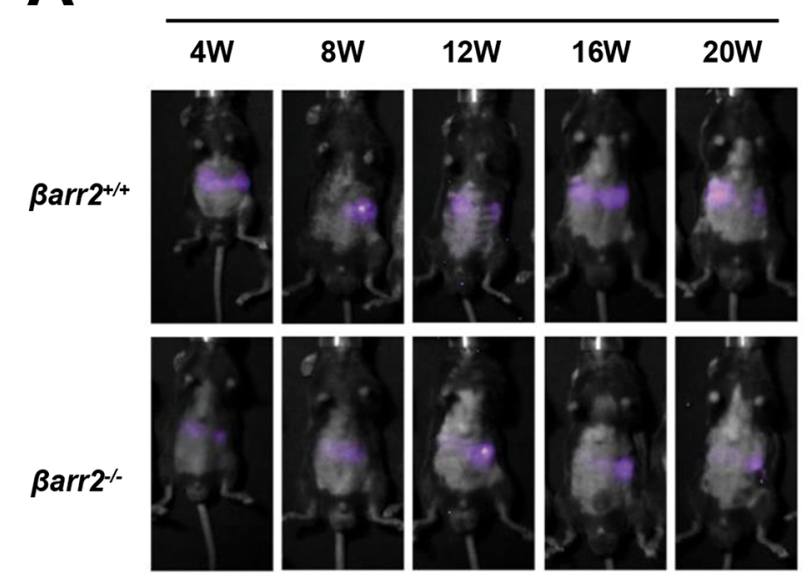

B

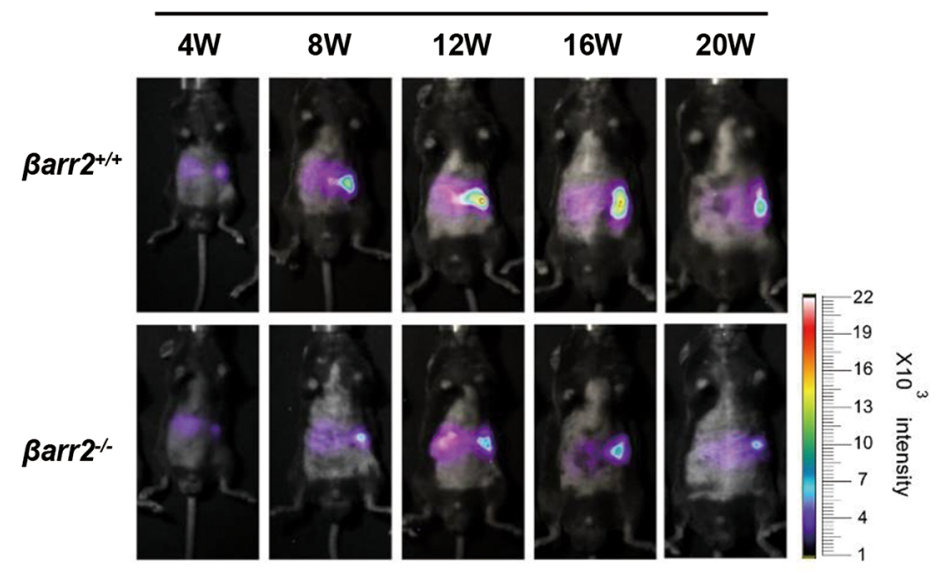

D
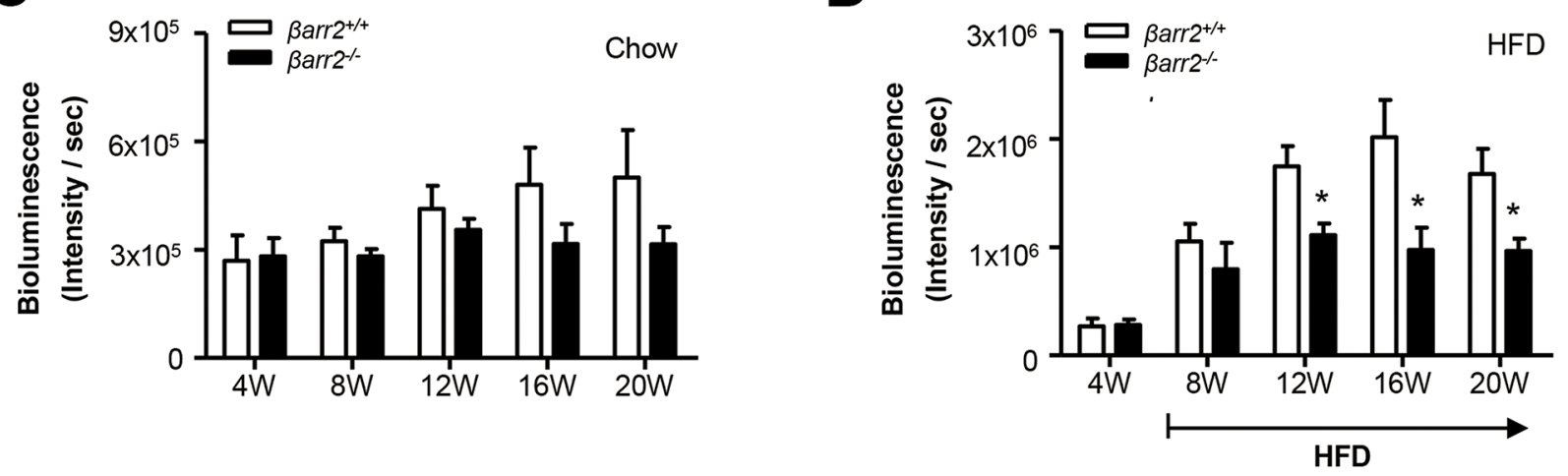

Figure 2. Dynamic changes of $\beta$-cell mass in MIP-TF- $\beta$ arr $2^{-/-}$mice. (A, B) MIP-TF- $\beta$ arr $2^{+/+}$and MIP-TF- $\beta$ arr2 ${ }^{-/-}$mice fed either (A) a chow diet or (B) a HFD were imaged at 4, 8, 12, 16 and 20 wks. Representative bioluminescence images of MIP-TF- $\beta$ arr2 ${ }^{+/+}$and MIP-TF- $\beta$ arr2 ${ }^{-/}$ mice are shown. (C, D) Quantification of signal intensity corresponding to the pancreatic area in MIP-TF- $\beta$ arr $2^{+/+}$and MIP-TF- $\beta$ arr $2^{-/}$mice $(n=4-6) .{ }^{*} P<0.05$ versus MIP-TF- $\beta a r r 2^{+/+}$mice.

a microarray analysis was performed to compared the gene expression between islets isolated from $\beta_{a r r 2}{ }^{-/}$and $\beta a r r 2^{+/+}$ mice. In total, 819 genes were found to be changed significantly in the $\beta$ arr2-null islets. Among them, 558 genes were upregulated and 261 genes were downregulated. As shown in Figure 6A, components in the JNK/mitogen-activated protein kinase (MAPK) signaling pathway were significantly altered in $\beta a r r 2^{-/}$islets (35 genes involved, 13\% of the total genes in the pathway, enrichment test $P<0.01$ ) with upregulation of gene expression in MAPK-upstream protein kinase (MUK)/MAP kinase kinase 7 (MKK7)/ JNK1/2/c-Jun cascade. The real-time PCR validated the expression pattern of MKK7 observed in the array analysis (Figure 6B). Moreover, exposure of INS-1 (832/13) to high glucose or FFA led to the phosphorylation of JNK, whereas overexpression of $\beta$ arr2 in the cells diminished the JNK activation (Figure 6C), suggesting a role of $\beta$ arr2 in the regulation of the JNK signaling pathway. To confirm findings in islets, the gain- and loss-of-function experiments were performed in the $\beta$-cell line. As shown in Figure 6D, knocking down of $\beta$ arr2 in INS-1 (832/13) cells with shRNA significantly aggravated the high glucose- and FFA-induced cell death to 1.8-fold (glucose) and 1.6-fold (FFA). The addition of SP600125, a JNK inhibitor, dose-dependently abolished the above effect. In contrast, the cytoprotective effects of $\beta$ arr 2 on high glucose- and FFA-induced death were diminished dose-dependently in the presence of JNK1 (Figure 6E). Taken together, these observations suggested that $\beta$ arr 2 modulates $\beta$-cell survival through the regulation of proapoptosis JNK pathway.

\section{DISCUSSION}

In the present study, using a real-time tracing imaging technique, we characterized the dynamic changes of $\beta$-cell mass in $\beta a r r 2-n u l l$ mice under HFD conditions from 4 to $20 \mathrm{wks}$ and provided in vivo evidence demonstrating that 
A

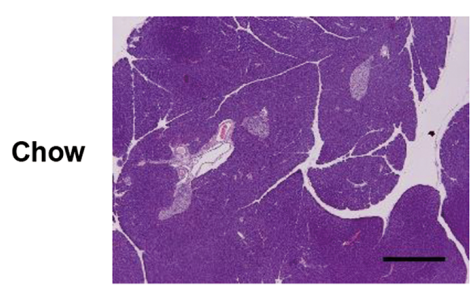

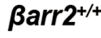

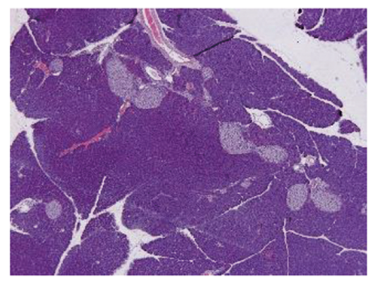

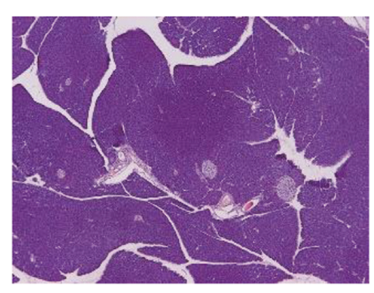

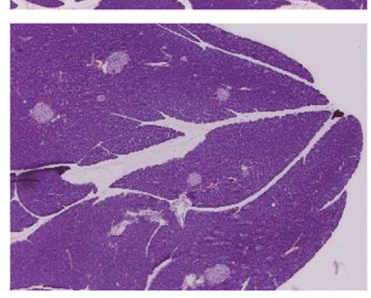

B

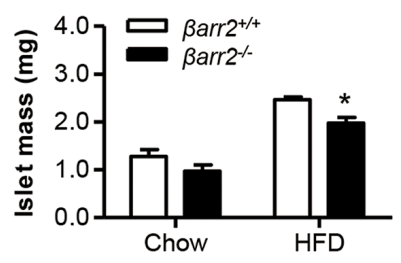

C

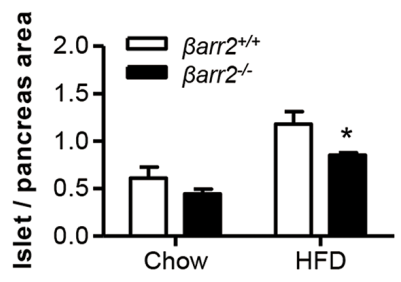

D

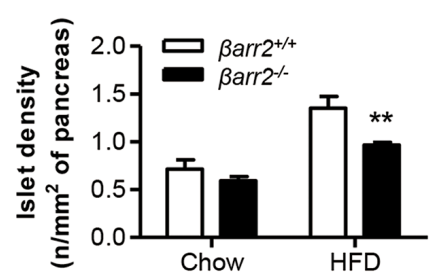

E

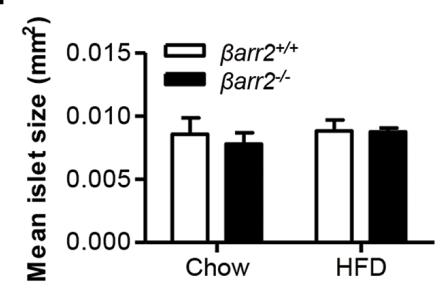

$\mathbf{F}$

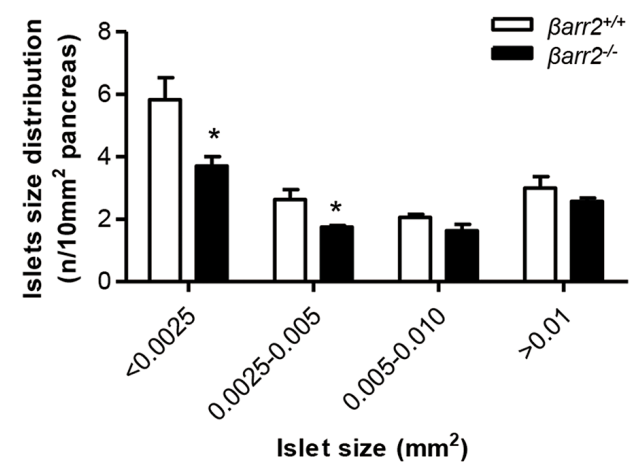

Figure 3. Quantification of islet mass in pancreas sections. (A) Pancreas sections (8-10 sections per mouse) of 16 -wk-old $\beta$ arr $2^{+/+}$and $\beta a r r 2^{-1}$ mice fed a chow diet or a HFD were stained with H\&E. Representative micrographs of H\&E staining of pancreatic sections from $\beta a r r 2^{+/+}$and $\beta a r r 2^{-/-}$mice. Scale bar: $500 \mu \mathrm{m}$. (B) Quantification of islet mass, (C) percentage islet area relative to pancreas, (D) islet density, (E) mean islet size and (F) islet size distribution of $\beta a r r 2^{+/+}$and $\beta a r r 2^{-/}$mice fed with a HFD $(n=3-5)$. ${ }^{*} P<0.05,{ }^{* *} P<0.01$, versus $\beta a r r 2^{+/+}$mice. deficiency of $\beta$ arr2 in mice led to much earlier and more severe decompensation of $\beta$-cell mass under HFD (Figure 2). Moreover, we provide evidence supporting the novel roles of $\beta$ arr2 in protection of $\beta$-cells from glucotoxicity- and lipotoxicity-induced cell death (Figure 5) through inhibition of proapoptosis JNK pathway activation (Figure 6) and in regulation of cell proliferation through cyclin D2 and p21 expression modulation (Figure 4). Revealing novel roles and mechanisms of $\beta$ arr2 in regulating dynamic $\beta$-cell mass changes is essential to provide information necessary for the development of new therapy strategies for T2D.

It is well known that $\beta$-cell mass changes during the development and progression of T2D (1-4). Mass quantification with noninvasive approaches is important for basic science and clinical studies. However, quantification of $\beta$-cell mass in vivo is relatively difficult due to the lack of reliable and noninvasive biomarkers for cells (24). Recently, the use of in vivo imaging techniques including positron-emission tomography (PET) and single-photon emission computed tomography (SPECT) with isotope-labeled ligands [such as ${ }^{18}$ F-fluoropropyl-(+)-DTBZ and ${ }^{111}$ In-labeled exendin] have been utilized in the field of human $\beta$-cell image studies (25-27). Likewise, BLI has been widely used with luciferase transgenic mice to evaluate $\beta$-cell mass under both normal and pathological conditions $(17,28)$. BLI is advantageous because it saves the animals from being killed and allows sequential studies in the same animal. In contrast to other imaging methods, BLI additionally provides quantifiable data with high throughput and inherently low background. However, a drawback of limited tissue penetration in BLI makes it impossible to apply to humans. Nevertheless, the lower cost of BLI compared with other imaging methods and good correlation with pancreatic $\beta$-cell mass makes BLI highly useful for studies in small animals.

In the present study, to trace the effect of $\beta$ arr2 loss on the changes of $\beta$-cell mass during mouse growth in real 


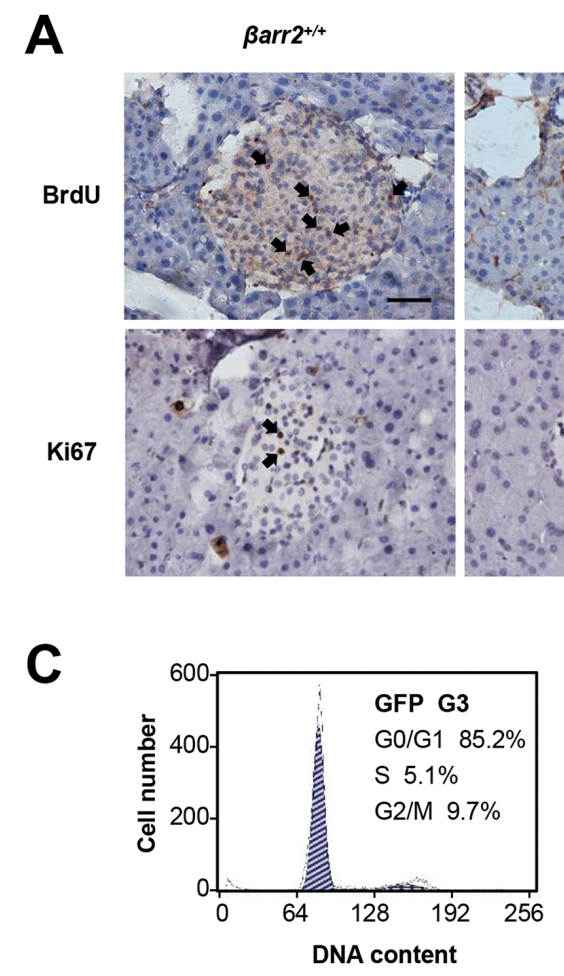

Barr2- $^{--}$

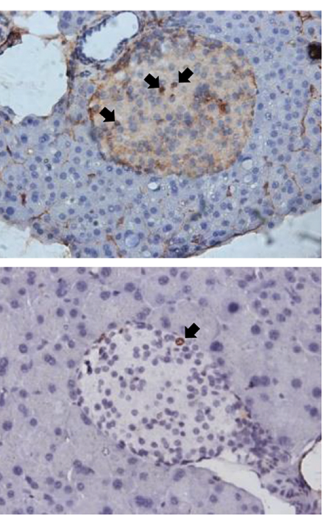

B
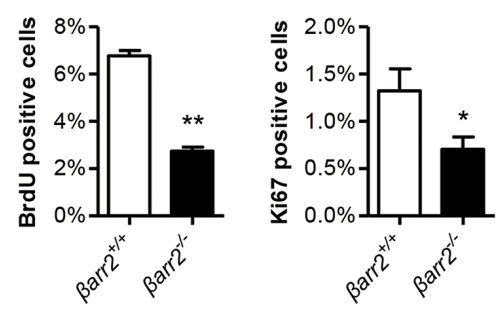
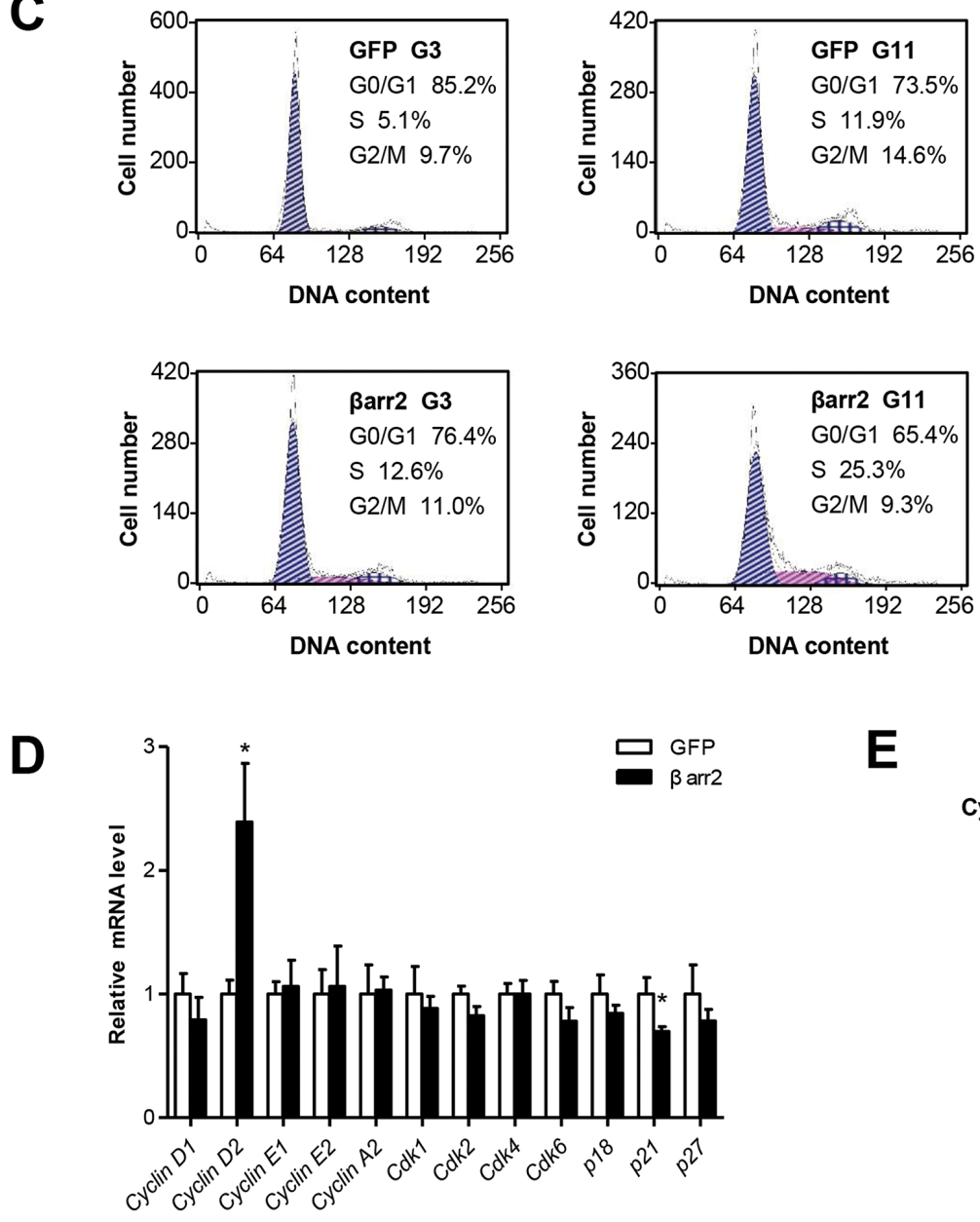

E

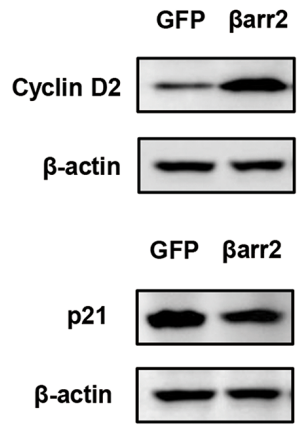

Figure 4. The effect of $\beta$ arr2 on $\beta$-cell proliferation. (A) Representative micrographs of BrdU and Ki67 staining in islets of $\beta a r r 2^{+/+}$and Barr $2^{-/-}$mice. Scale bar: $50 \mu \mathrm{m}$. Arrows: BrdU- or Ki67-positive cells. (B) Quantification of BrdU- or Ki67-positive cells in the total islet cells $(n=3-5)$. (C) Cell cycle distribution analyzed by flow cytometry in INS-1 (832/13) cells infected with adenovirus expressing GFP or $\beta$ arr2 and exposed to $3 \mathrm{mmol} / \mathrm{L}$ (G3) or $11 \mathrm{mmol} / \mathrm{L}$ (G11) glucose. (D) Relative mRNA transcriptional levels of cell cycle genes from INS-1 (832/13) cells with $\beta$ arr2 overexpression ( $n=6-8$ ). Expression of mRNA was normalized with $\beta$-actin. (E) Cyclin D2 and p21 protein levels in INS-1 (832/13) cells infected with adenovirus expressing GFP or $\beta$ arr2. Pictures are representative of four independent experiments. ${ }^{*} P<0.05,{ }^{* *} P<0.01$, versus control. 
A

6.1

G30
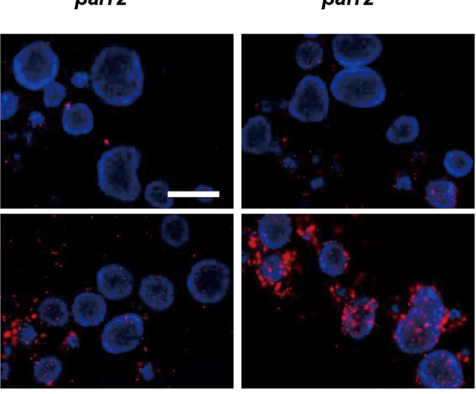

BSA
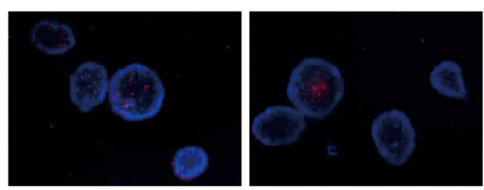

PA0.4

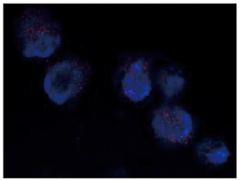

B
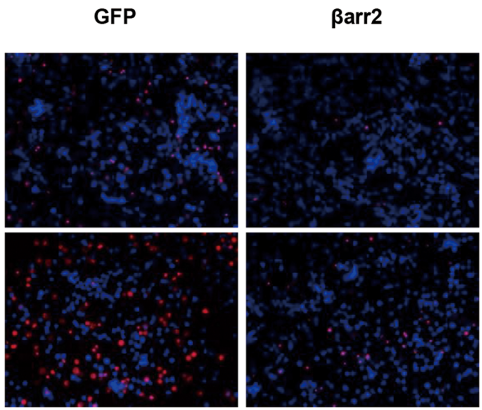

BSA
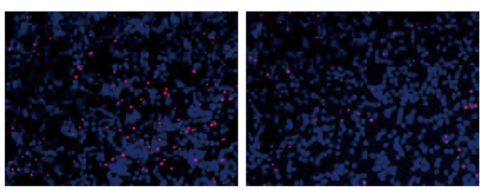

PA0.4
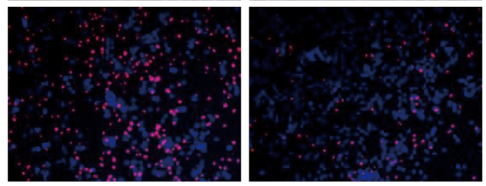

C

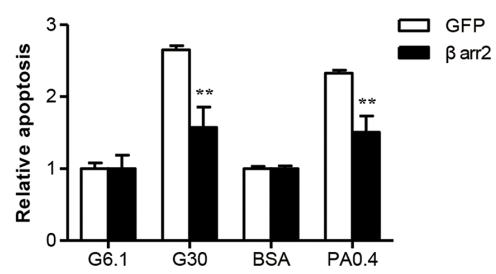

Figure 5. $\beta$ arr2 protected $\beta$-cell against high glucose- and free fatty acids-induced apoptosis. (A, B) Islets isolated from 16-wk-old $\beta$ arr2 ${ }^{+/+}$and $\beta$ arr2 $2^{-/}$mice and INS-1 (832/13) cells infected with adenoviruses expressing GFP or $\beta$ arr 2 were exposed to $6.1 \mathrm{mmol} / \mathrm{L}$ (G6.1) or $30 \mathrm{mmol} / \mathrm{L}$ (G30) glucose, or BSA alone or with $0.4 \mathrm{mmol} / \mathrm{L}$ palmitate (PA0.4). Representative fluorescence micrographs after double staining with propidium iodide (red) and Hoechst 33324 (blue) of islets (A) and INS-1 (832/13) cells (B) from five independent experiments are shown. Scale bar: $200 \mu \mathrm{m}$. (C) Quantitative percentage of apoptotic cells in the total INS-1 $(832 / 13)$ cells $(n=5) .{ }^{* *} P<0.01$ versus GFP.

time, $\beta a r r 2^{-/-}$mice were interbred with MIP-TF mice. Consistent with previous findings, HFD induced an adaptive increase of $\beta$-cell mass in mice (17). During a prolonged observation period, we noticed a declining trend in $\beta$-cell mass after 16 wks in HFD-fed mice, supporting the transition from compensation to decompensation during increasing metabolic demand (29). Knocking out $\beta a r r 2$ led to an earlier and more severe decompensation of $\beta$-cell mass in mice fed a HFD (Figure 2). Our in vivo findings are in agreement with fixed our specimen findings (Figure 3 ) and by those of Ravier et al. reporting with female mice (14) when we prepared our manuscript. Moreover, our histological study revealed that decreased islet density, rather than mean islet size, was the major outcome in HFD-fed $\beta a r r 2^{-/-}$mice (Figure 3). Similar phenomena were reported from autopsy findings in nondiabetic adults (21) and in carriers with TCF7L2 rs7903146 (T/T), a risk allele for T2D (30). Taken together, our results indicate that loss of small islets in $\beta a r r 2^{--}$mice contributes to the failure to adapt $\beta$-cell mass under metabolic stress. However, the data reported on the effect of $\beta$ arr2 deletion on glucose-stimulated insulin secretion are controversial $(11,14)$. This discrepancy may result from the islets isolated from different mice, as while we used islets from 12-wk-old male mice, Ravier et al. used islets from 6- to 7-month-old female mice. Further studies may be needed to explore the possibility.

The failure of $\beta$-cells to compensate for the lost mass under metabolic stress observed in $\beta a r r 2^{-/-}$mice indicates the role of $\beta$ arr 2 in regulation of $\beta$-cell mass. One mechanism underlying the loss of $\beta$-cell mass in HFD-fed $\beta a r r 2^{-/}$mice is likely the consequence of reduced $\beta$-cell proliferation via modulation of cell cycle regulation. We showed in the study that both BrdU- and Ki67-positive cells were decreased significantly in islets with $\beta$ arr2 deletion. Overexpression of $\beta$ arr2 increased the proportion of cells in the $S$ and $G_{2} / M$ phases of the cell cycle with concomitant upregulation of cyclin D2 and attenuation of p21 expression in INS-1 (832/13) cells (Figure 4). Both cyclin D2 and p21 are cell cycle-related proteins involved in regulating release of the $G_{1}$ brake and entry of cell cycle $(31,32)$. Cdk inhibitor p21 functions as a molecular brake during $\beta$-cell expansion and is upregulated during pregnancy and mitogen stimulation to avoid excessive proliferation (33-36). Cyclin D2 is the major $D$-type cyclin in $\beta$-cells and plays a vital role in the regulation of adult $\beta$-cell proliferation $(31,37)$. Knocking out cyclin D2 in mice resulted in a four-fold reduction in $\beta$-cell mass and led to development of impaired glucose tolerance or even diabetes in these mice $(38,39)$. In contrast, overexpression of cyclin D2 in human islets increased BrdU-positive cells (40). While cyclin D2 might be a regulator driving adaptive $\beta$-cell proliferation, it is currently unclear how $\beta$ arr2 manipulates cyclin D2 transcription in $\beta$-cells. It is known that activation of the insulin receptor/Akt signaling pathway was associated with $\beta$-cell proliferation (41). $\beta$ arr2 has been reported to enhance insulin-stimulated Akt activity in mouse liver, skeletal muscle and 

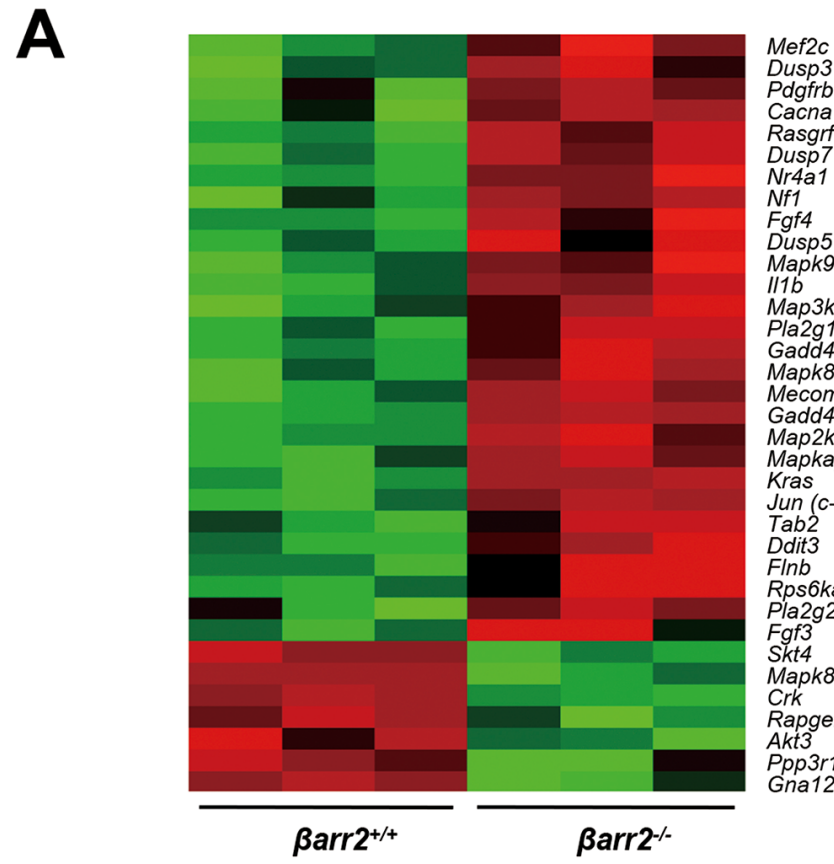

Dusp3

Pdgfrb

Cacna1a

Rasgrf
Dusp7

Nr4a1

Nf1

Fgf4

Dusp5

Mapk9 (Jnk2)

$111 b$

Map3k12 (Muk)

Pla2g1b

Gadd45b

Mapk8 (Jnk1)

Mecom

Gadd45g

Map2k7 (Mkk7)

Mapkapk5

Kras

Jun (c-Jun)

Tab2

Ddit3

Flnb

Rps6ka2

Pla2g2f

Fgf3

Skt4

Crk

Rapgef2

Akt3

Ppp3r

Gna12

Barr2 $^{+/+}$

Barr2--
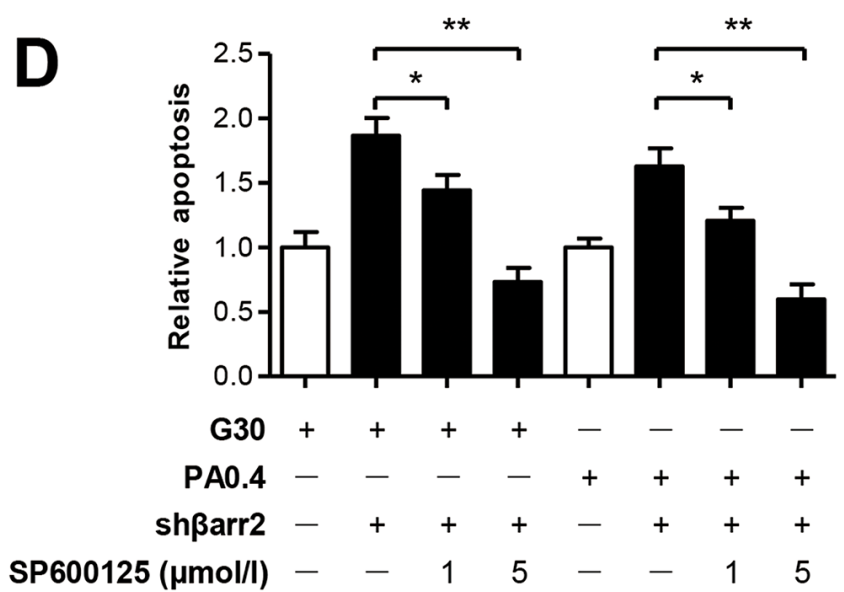

B

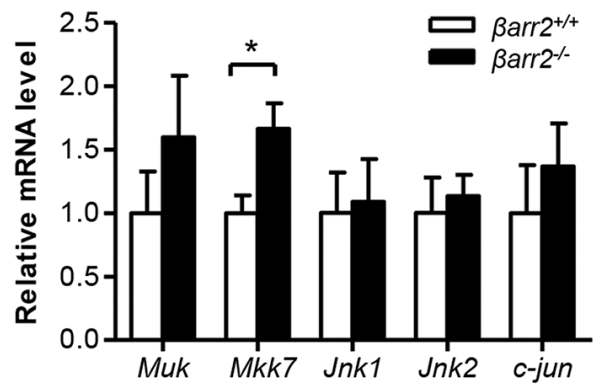

C
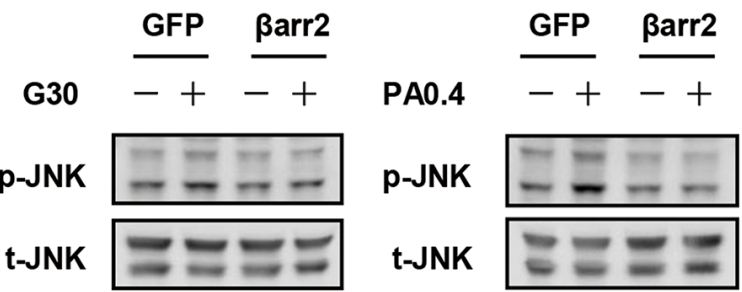

E

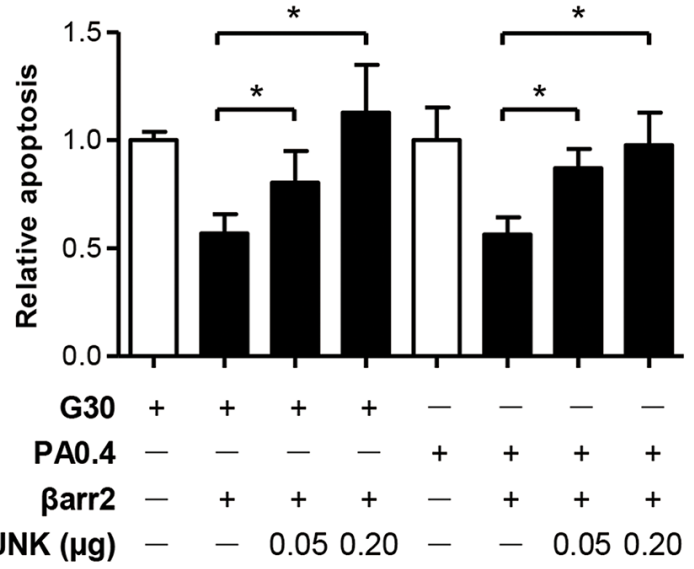

Figure 6. $\beta$ arr2 inhibited FFAs or glucose-induced activation of the JNK pathway in $\beta$-cells. (A) Total RNA was obtained from islets of $\beta$ arr2 ${ }^{+/+}$ and $\beta$ arr $2^{--}$mice and subjected to whole-genome expression profiling using Affymetrix arrays. Heat diagram depicting genes in the JNK/ MAPK pathway for which expression was significantly upregulated (28 genes) and downregulated (7 genes) in the islets of $\beta a r r 2^{-/-}$as compared with $\beta$ arr $2^{+/+}$animals $(n=3)$. (B) Quantification of islet mRNA expression in the JNK pathway normalized with $\beta$-actin $(n=4-6)$. (C) INS-1 (832/13) cells were infected with adenovirus encoding GFP or $\beta$ arr2 and assayed for p-JNK and total JNK expression in the presence or absence of $30 \mathrm{mmol} / \mathrm{L}$ glucose (G30) and $0.4 \mathrm{mmol} / \mathrm{L}$ palmate (PA0.4) for $24 \mathrm{~h}$. Pictures are representative of four independent experiments. (D, E) INS-1 (832/13) cells were infected with either adenovirus-encoding shRNA of $\beta$ arr2 (sh $\beta$ arr2) (D) or $\beta$ arr2 (E) and incubated with G30 or PA0.4 in the presence of SP600125 (D) or plasmid-expressing JNK (E). Data were presented as fold-change over cells infected with scrambled shRNA ( $D$, white bar) or GFP (E, white bar) $(n=4) .{ }^{*} P<0.05,{ }^{* *} P<0.01$, versus indicated group. Muk, mitogen-activated protein kinase upstream protein kinase; Mkk7, mitogen-activated protein kinase kinase 7. Jnk, C-Jun N-terminal kinase.

adipose tissue (10). In INS-1E cells, activation of Akt is associated with phosphorylation of FoxO1a and prevents FoxO1a from translocation into the nucleus, thus releasing transcription repression of cyclin
$D 2$ (42). It is, thus, speculated that the effect of $\beta$ arr2 on cyclin D2 transcription might be through the Akt/FoxO1a pathway. Further studies are needed to explore that possibility.
Moreover, we showed in the present study that $\beta$ arr 2 protected $\beta$-cells from glucolipotoxicity-induced cell apoptosis. The antiapoptosis effects for $\beta$ arr2 are in agreement with several previous studies 
in other cell lines $(43,44)$. Sun et al. reported that overexpression of $\beta$ arr2 decreased the percentage of apoptosis and inhibited caspase- 3 activation in endometrial cancer (44). Furthermore, we proved, for first time, that the cytoprotective effect of $\beta$ arr2 was mediated through its inhibition of the JNK pathway activated by high levels of glucose and FFA. The following lines of evidence support this conclusion: a) deletion of $\beta a r r 2$ in islets enhanced the gene transcription in the JNK pathway shown in microarray, and aggravated cell death; b) overexpression of $\beta$ arr2 inhibited the phosphorylation of JNK induced by glucose and FFA and protected $\beta$-cell from high levels of glucose- and FFA-induced apoptosis; and c) the cytoprotective effect of $\beta$ arr 2 on cells could be abolished dose-dependently in JNK1-overexpression cells. JNK1 and JNK2 are stress-activated proapoptotic proteins in pancreatic islets (45). Knockdown of JNK1 or JNK2 has been reported to protect $\beta$-cells against cytokine-induced apoptosis and to improve $\beta$-cell viability by $40 \%$ and $60 \%$, respectively (45). Our result was in line with the report by Zhao et al., in which double knockout ßarr1/2 in MEF cells greatly enhanced interleukin-8-induced phosphorylation of JNK (46). However, the mechanisms of $\beta a r r 2$ in the regulation of genes transcription in JNK pathway are still unclear.

\section{CONCLUSION}

In summary, $\beta$ arr2 plays roles in protection of $\beta$-cells against glucolipotoxicityinduced cell death through inhibition of the JNK pathway and in regulation of $\beta$-cell proliferation associated with modulation of cell cycle regulatory genes. Loss of $\beta$ arr2 leads to limited $\beta$-cell mass expansion under metabolic stress. Taken together with our previous discoveries $(10,11)$, we conclude that $\beta$ arr2 plays an important role in the development of T2D by modulating peripheral insulin sensitivity, insulin secretion and $\beta$-cell mass.

\section{ACKNOWLEDGMENTS}

The authors thank Yiwen Liu and Yiqing He of the Molecular Biology Laboratory,
Shanghai Jiao Tong University School of Medicine, for preparation of the tile image of pancreas sections and performance of flow cytometer analysis. They also thank Yong Liu of the Institute for Nutritional Sciences, Shanghai Institute for Biological Sciences, Chinese Academy of Sciences, for the kind gift of INS-1 (832/13) cells; Gang Pei of the Institutes for Biological Sciences, Chinese Academy of Sciences, for his kind gifts of adenovirus-expressing $\beta$ arr2 (Ad- $\beta$ arr 2) and its shRNA (Ad-shßarr2); and Yan Lu of the Shanghai Institute of Endocrinology and Metabolism, Shanghai Jiao Tong University School of Medicine, for kindly providing the plasmid expressing c-Jun N-terminal kinase-1 (JNK1). The study was funded by the Shanghai Committee of Science and Technology (11140900900), the National Natural Science Foundation of China (31340072) and Doctoral Innovation Fund Projects from the Shanghai Jiao Tong University of Medicine (BXJ201236).

\section{DISCLOSURE}

The authors declare that they have no competing interests as defined by Molecular Medicine, or other interests that might be perceived to influence the results and discussion reported in this paper.

\section{REFERENCES}

1. Meier JJ, Bonadonna RC. (2013) Role of reduced beta-cell mass versus impaired beta-cell function in the pathogenesis of type 2 diabetes. Diabetes Care. 36 Suppl 2:S113-9.

2. Donath MY, Halban PA. (2004) Decreased beta-cell mass in diabetes: significance, mechanisms and therapeutic implications. Diabetologia. 47:581-9.

3. Weir GC, Bonner-Weir S, Leahy JL. (1990) Islet mass and function in diabetes and transplantation. Diabetes. 39:401-5.

4. Meier JJ, et al. (2012) Pancreatic diabetes manifests when beta cell area declines by approximately 65\% in humans. Diabetologia. 55:1346-54.

5. DeWire SM, Ahn S, Lefkowitz RJ, Shenoy SK. (2007) Beta-arrestins and cell signaling. Annu. Rev. Physiol. 69:483-510.

6. Goodman OB, Jr., et al. (1996) Beta-arrestin acts as a clathrin adaptor in endocytosis of the beta2-adrenergic receptor. Nature. 383:447-50.

7. Walther C, Ferguson SS. (2013) Arrestins: role in the desensitization, sequestration, and vesicular trafficking of G protein-coupled receptors. Prog. Mol. Biol. Transl. Sci. 118:93-113.

8. Beaulieu JM, et al. (2008) A beta-arrestin 2 signaling complex mediates lithium action on behavior. Cell. 132:125-36.

9. McDonald PH, et al. (2000) Beta-arrestin 2: a receptor-regulated MAPK scaffold for the activation of JNK3. Science. 290:1574-7.

10. Luan B, et al. (2009) Deficiency of a beta-arrestin-2 signal complex contributes to insulin resistance. Nature. 457:1146-9.

11. Zhang M, et al. (2013) Loss of beta-arrestin2 mediates pancreatic-islet dysfunction in mice. Biochem. Biophys. Res. Commun. 435:345-9.

12. Kim J, et al. (2008) Beta-arrestins regulate atherosclerosis and neointimal hyperplasia by controlling smooth muscle cell proliferation and migration. Circ. Res. 103:70-9.

13. Sun WY, et al. (2013) Depletion of beta-arrestin2 in hepatic stellate cells reduces cell proliferation via ERK pathway. J. Cell. Biochem. 114:1153-62.

14. Ravier MA, et al. (2014) $\beta$-Arrestin2 plays a key role in the modulation of the pancreatic beta cell mass in mice. Diabetologia. 57:532-41.

15. Bohn LM, et al. (1999) Enhanced morphine analgesia in mice lacking beta-arrestin 2. Science. 286:2495-8.

16. Zhang Y, Liu C, Wei B, Pei G. (2013) Loss of beta-arrestin 2 exacerbates experimental autoimmune encephalomyelitis with reduced number of Foxp3(+) CD4(+) regulatory T cells. Immunology. 140:430-40.

17. Yong J, et al. (2011) Multimodality imaging of beta-cells in mouse models of type 1 and 2 diabetes. Diabetes. 60:1383-92.

18. Wang C, et al. (2013) Deficiency of APPL1 in mice impairs glucose-stimulated insulin secretion through inhibition of pancreatic beta cell mitochondrial function. Diabetologia. 56:1999-2009.

19. Hohmeier HE, et al. (2000) Isolation of INS-1derived cell lines with robust ATP-sensitive $\mathrm{K}+$ channel-dependent and -independent glucose-stimulated insulin secretion. Diabetes. 49:424-30.

20. Wang P, et al. (2003) Beta-arrestin 2 functions as a G-protein-coupled receptor-activated regulator of oncoprotein Mdm2. J. Biol. Chem. 278:6363-70.

21. Kou K, Saisho Y, Sato S, Yamada T, Itoh H. (2014) Islet number rather than islet size is a major determinant of beta- and alpha-cell mass in humans. J. Clin. Endocrinol. Metab. 99:1733-40.

22. Scholzen T, Gerdes J. (2000) The Ki-67 protein: from the known and the unknown. J. Cell. Physiol. 182:311-22.

23. Lu Y, et al. (2004) Bioluminescent monitoring of islet graft survival after transplantation. Mol. Ther. 9:428-35.

24. Ichise M, Harris PE. (2010) Imaging of beta-cell mass and function. J. Nucl. Med. 51:1001-4.

25. Goland R, et al. (2009) 11C-dihydrotetrabenazine PET of the pancreas in subjects with long-standing type 1 diabetes and in healthy controls. J. Nucl. Med. 50:382-9. 
26. Normandin MD, et al. (2012) In vivo imaging of endogenous pancreatic beta-cell mass in healthy and type 1 diabetic subjects using 18F-fluoropropyl-dihydrotetrabenazine and PET. J. Nucl. Med. 53:908-16.

27. Brom M, et al. (2014) Non-invasive quantification of the beta cell mass by SPECT with 111In-labelled exendin. Diabetologia. 57:950-9.

28. Virostko J, et al. (2010) Bioluminescence imaging in mouse models quantifies beta cell mass in the pancreas and after islet transplantation. Mol. Imaging Biol. 12:42-53.

29. Sachdeva MM, Stoffers DA. (2009) Minireview: Meeting the demand for insulin: molecular mechanisms of adaptive postnatal beta-cell mass expansion. Mol. Endocrinol. 23:747-58.

30. Le Bacquer O, et al. (2012) TCF7L2 rs7903146 impairs islet function and morphology in non-diabetic individuals. Diabetologia. 55:2677-81.

31. Kushner JA. (2006) Beta-cell growth: an unusual paradigm of organogenesis that is cyclin D2/Cdk4 dependent. Cell Cycle. 5:234-7.

32. Hernandez AM, et al. (2013) Upregulation of p21 activates the intrinsic apoptotic pathway in beta-cells. Am. J. Physiol. Endocrinol. Metab. 304:E1281-90.

33. Blandino-Rosano M, et al. (2012) Enhanced beta cell proliferation in mice overexpressing a constitutively active form of Akt and one allele of p21Cip. Diabetologia. 55:1380-9.

34. Cozar-Castellano I, et al. (2006) Evaluation of beta-cell replication in mice transgenic for hepatocyte growth factor and placental lactogen: comprehensive characterization of the G1/S regulatory proteins reveals unique involvement of p21cip. Diabetes. 55:70-7.

35. Hughes E, Huang C. (2011) Participation of Akt, menin, and p21 in pregnancy-induced beta-cell proliferation. Endocrinology. 152:847-55.

36. Liu Y, Martindale JL, Gorospe M, Holbrook NJ. (1996) Regulation of p21WAF1/CIP1 expression through mitogen-activated protein kinase signaling pathway. Cancer Res. 56:31-5.

37. Chen S, Shimoda M, Chen J, Matsumoto S, Grayburn PA. (2012) Transient overexpression of cyclin D2/CDK4/GLP1 genes induces proliferation and differentiation of adult pancreatic progenitors and mediates islet regeneration. Cell Cycle. 11:695-705.

38. Kushner JA, et al. (2005) Cyclins D2 and D1 are essential for postnatal pancreatic beta-cell growth. Mol. Cell. Biol. 25:3752-62.

39. Georgia S, Bhushan A. (2004) Beta cell replication is the primary mechanism for maintaining postnatal beta cell mass. J. Clin. Invest. 114:963-8.

40. Fiaschi-Taesch NM, et al. (2010) Induction of human beta-cell proliferation and engraftment using a single G1/S regulatory molecule, cdk6. Diabetes. 59:1926-36.

41. Tuttle RL, et al. (2001) Regulation of pancreatic beta-cell growth and survival by the serine/threonine protein kinase Akt1/PKBalpha. Nat. Med. 7:1133-7.
42. You H, Laychock SG. (2009) Atrial natriuretic peptide promotes pancreatic islet beta-cell growth and Akt/Foxo1a/cyclin D2 signaling. Endocrinology. 150:5455-65.

43. Revankar CM, Vines CM, Cimino DF, Prossnitz ER. (2004) Arrestins block G protein-coupled receptor-mediated apoptosis. J. Biol. Chem. 279:24578-84.

44. Sun X, et al. (2010) Beta-arrestin 2 modulates resveratrol-induced apoptosis and regulation of Akt/GSK3ss pathways. Biochim. Biophys. Acta. 1800:912-8.

45. Abdelli S, et al. (2009) JNK3 is abundant in insulin-secreting cells and protects against cytokine-induced apoptosis. Diabetologia. 52:1871-80.

46. Zhao M, Wimmer A, Trieu K, Discipio RG, Schraufstatter IU. (2004) Arrestin regulates MAPK activation and prevents NADPH oxidase-dependent death of cells expressing CXCR2. J. Biol. Chem. 279:49259-67.

Cite this article as: Lin Z, et al. (2016) Deletion of $\beta$-arrestin2 in mice limited pancreatic $\beta$-cell expansion under metabolic stress through activation of the JNK pathway. Mol. Med. 22:74-84. 